TITLE: A Measurement of the Gravitational Acceleration of the Antiproton: An Experimental Overview

AUTHOA(S): Nelson Jarmie

SUBMitteu TO: E1ghth Conference on the Applications of Accelerators in Research and Industry, 10-12 November 1986, Denton Texas

\title{
DISCLAIMEK
}

This report was propared as an account of work oponeosed by an egency of the United Stalea Government. Neither the Unlied States Government nor any asency thereof, nor any of their employees, makes any warranty, expreas or implied, or asumes any leeal liability or rosponal. billity for the eccuracy, enmpletenous, or usefulness of eny inforination, apparatus, product, or process disclosed, of represents that its use would not infringe privately owned rights. Refor. enco herein to any specific commercial product, process, or service by trade name, trudemark, inanufacturer, or otherwise does not necessarily consiltute or imply its endormement, recom. mendation, or favoring by the United States Government or any agercy thereof. The views and opinion of authorn expreseed herein do not necessarlly atnte or reflect those of the United Siatee Government of eny agency thereor. 
Invited Paper

for the 1986 Denton Meeting, Eight Conference on the

Application of Accelerators in Research and Industry

10-12 November 1986

\title{
A MEASUREMENT OF THE GRAVITATIONAL ACCELERATION OF THE ANTIPROTON: AN EXPERIMENTAL OVERVIEW
}

NELSON JARMIE, Los Alamos National Laboratory

Los Alamos, NM, 87545, USA

\begin{abstract}
An ambitious experiment is being developed to measure the force on the antiproton due to the gravitational field of the earth. The technique consists in obtaining antiprotons of the lowest energy possible from the LEAR facility at CERN, decelerating them further in an external beam line, trapping and cooling them to ultralow energy, and measuring their gravitational acceleration by time-of-1light methods. The experiment has been granted CERN approval (PS-200). Present plans and initlal development etforts are described.
\end{abstract}




\title{
A MEASUREMENT OF THE GRAVITATIONAL ACCELERATION
}

\section{OF THE ANTIPROTON: AN EXPERIMEN'TAL OVERVIEW}

\author{
NELSON JARMIE, Los Alamos National Laboratory \\ Los Alamos, NM, 87545, USA
}

\section{Introduction}

An adventurous and difficult experiment to measure the gravitational Interaction of antimatter (an antiproton) with matter (the earth) is being planned. The effect of earth's gravity on other fundamintal particles has been measured (3), but no measurement of the gravitational interaction of antimatter with either matter or antimatter has ever been made. Recent theory $(1,2,3)$ suggest that the antimatter-matter gravitational interaction could be slgnific antly different than the matter-matter interactlon with which we are so familiar. One typical estimate is that the antimatier-matter Interaction could be a factor of 3 stronger (4). In keeping with the nature of this conference I will not detall the theoretical background, but I shall first outline the basic exferlment as plannec by our scientific collaboration developing the project (5), then discuss some of the more challenging aspects of the work, and finally comment on our current progress.

\section{The Baslc Exporiment}

.4 simple scirematic of the experiment is shown in flgure 1. Antiprotons in a thermal (statistical) dlstribution in an electromagnetic trap are released to traverse upwards through a $1-\mathrm{m}$ shielded drift tube to a detector, most likely a multichannel plate detector (MCP). The time of flight (TOF) of the particles from release to detection is recorded. At somie slow velocity, because of the gravitational attraction, the particles will fall back and not reach the celector. This cutoff time, $T_{c}=(2 \mathrm{~L} / \mathrm{g})^{112}$, about 0.45 seconds, Yallows the detormination of $g$ if the drift length $L$ is known.

\section{The Real Experimerit}

Transtorming the basic experiment into reality introdices numerous and challenging complicatlons.

a. For a $1-\mathrm{m}$ drift tube, tho release energy of the particle with the cutoff TOF is about $10^{-7} \mathrm{eV}(5 \mathrm{~m} / \mathrm{s})$; gravity is weakl Supplying sufflcient numbers of antiprotons to map out the TOF spectrum in the region of the cutoff is a problem. If the antiproton cluster in the launch trap has been cooled to llquid hellum temperaturia, $4 \mathrm{~K}$, the mean energy of the partisies is about $10^{-3} \mathrm{oV}(1 \mathrm{meV})$, and few particles have a low enough energy to be useful. Monte Carlo studies indicate that roughly $10^{7}$ particles will have to be launched from a trap at $4 \mathrm{~K}$ to measure $g$ to $1 \%$. In order to obtaln sufficlent numbers of antiprotons, we plan to pertorm the experiment at the Low Energy Antiproton Ring (LEAR) lacillty at CERN in Genova, Switzerland, where our proposal (6) has been accepted as experiment PS-200. Detalls of this experiment ha'se been discussed prevlously (7-11).

b. In order not to compete with gravitation, electromagnetlc forces must be 
extremely small in the drift tube region: less than $10^{-7} \mathrm{~V} / \mathrm{m}$ and 1 part in $10^{-5}$ variation in the magnetic guide field needed for such low energy Darticles.

c. The drift length $L$ will not be known well because of electric field penetration into the drift tube. An $\mathrm{H}^{-}$ion has the same electric charge and very nearly the same inertial mass and magnetic moment as an antiproton. An essentiai part of the experiment will be to repeat the measurements using $\mathrm{H}^{-}$ions for a calibration and comparison. Thus $\mathrm{H}^{-}$ion sources will be needed: at $20 \mathrm{keV}$ for tests and development, at $2 \mathrm{MeV}$ for checkout of the deceleration and final experiment setup at Los Alamos, and at $2 \mathrm{MeV}$ from LEAR for beam alignment and tuning. $D^{-}$ and $\mathrm{O}^{-}$beams will provide different mass ions to test and help understand the time-of-flight experiment.

d. Extremely low vacuums will be needed, on the order of $10^{-14}$ Torr, to avoid antiproton annihilation and $\mathrm{H}^{-}$neutralization by the residual gas atoms.

e. The antiprotons created at the CERN facility at about $3.6 \mathrm{GeV} / \mathrm{c}(2.7 \mathrm{GeV})$ must be decelerated, (trapped) and cooled by 16 orders of maynitude in energy to obtain $10^{\cdot 7} \mathrm{eV}$ particles, and this must be done without undue losses.

\section{Filling the Antiproton Reservolr}

A more complete schematic of the experiment is shown in figure 2. The antiprotons produced at CERN are collected, decelerated to $600 \mathrm{Me} V / \mathrm{C}$ and injected into LEAR for further deceleration and cooling. We hope to receive from LEAR a 200 ns burst of about $10^{8}$ or more $2 \mathrm{MeV}$ antiprotons. We will then decelerate this bunch to 20 i. $\mathrm{V}$ using a radiofrequency quadrupole (RFQ). A design study of the use of the RFQ as a decelerator has been given by J.H. Billen et al.(12). Transverse currents in the RFQ pole structure provide alternating electrir polarlties resulting in a transverse electric quadrupole field. This field produces focusing in one transverse plane and defocusing in the other. The fields reverse direction one half an RF period later to produce a net strong focusing effect. The pole tips are machined witu an oscillatory variation In radius to produce longltudinal accelerating (or decelerating) fields as well as transverse focusing fields. The strong focusing in an RFQ permits the preservation of good beam quality during deceleration. The RFQ frecuentiy offers the advantage of reduced size over an electostatlc system. A current design (13) gives an RFQ leilgth of less than 2 meters. An RF buncher $8 \mathrm{~m}$ upstream is necessary to create the initial $200 \mathrm{MHz}$ structure that the RFQ requires. Beam tuning and steering to insure that the single LEAR antiproton pulse will properly strike the first trap is critical, and development of suct, an ability for the $2 \mathrm{MeV}$ and 20 keV beam lines is underway. The necessary timing ior the LEAR beam bunch, chopped $H^{-}$beam, trap electrode voltage changes will be handled by a small computer; which will also analyze the experimental time-of-flight data as it is taken.

The $20 \mathrm{keV}$ partcles are then further decelerated to $5 \mathrm{keV}$ by elestrostatic forces, and then caught in an electomagnetic Penning trap $(9,14,15)$. Here an important transistion takes place from the particles having a directed enargy of a beam to a thermal distribution of a cluster held in the center of a trap. Particle confinement in a Penning trap is achieved by a combination of statlc electric and magnetic fields, with the electic fleld being that of an axlally symmetrlc quadrupole, the magnetlc field being unlform and in the axial diraction (the symmetry axis being the beam directlon.) Cooling the thermal particle bunch is pessible by several means. Stochastic cooling is being studied by collaboiators at the University of Genoa and Pisa In Italy, electron cooling at Rice University, and resistive cooling at Texas A\&M University and Los Alamos. Information on trapping and coulling 
September 25, 1986

processes is reported by Kenefick (16) and Church (17) at this conference.

The catching trap must be long in order to contain a large fraction of the antiproton burst. This length interferes with the harmonicity of the trap and thus its ability to cool the thermal distribution. An example of a design of a catching trap that also has some cooling ability is shown in figure 3. Here the shaping of the electric field with additional electrodes will allow efficient catching of the bunch and still retain enough resonant harmonicity to allow resistive cooling to be used to bring the teinperature down to about $10-100 \mathrm{eV}$ on the order of I hour or less. A 6-T magnet provides the axial field necessary for trap operation and for guiding the entering and exiting particles. "Closing the door" to catch the incoming particles is not a routine matter. 10 to 20 kilovolts in 10 's of ns must be applied with careful timing to the front electrode of the catching trap. A programmed high-voltage level shifter is under development which will provide the various potential changes in the trap electrode.

The now-small particle bunch is transfered to one or more smaller highly-compensated harmonic traps for additional and fast cooling (to a few Kelvin, $\sim 10^{-3} \mathrm{eV}$ ) and launching. Even after such cooling, the partisles of interest are far down on the slow part of the velocity distribution at $10^{-7} \mathrm{eV}$.

Successful development of a source of a large number of cold thermal antiprotons may open the door to a number of interesting experiments using antiptrotons or antihydrogen in addition to the gravity experiment.

\section{Vacuums and Cryostat Technology}

The annihilation cross section rises rapidly as the velocity of the antiproton falls (18). Vacuums of $10^{-10}$ to $10^{-12}$ Torr should suffice in the first catching trap. Such vacuums require painstaking but known techniques. In the launch-drift region whera the energies are very lou', the vacuums must be $10^{-14}$ Torr or better for adequate antiproton survival. This will necessitate complete enclosure at a temperature of $4 \mathrm{~K}$ or colder (19). The design of a system to provide all the voltage and signal leads, es well as a beam "trap door" (see Fig. 1), all to fit in the bore of a superconducting magnet, will be a stimulating challenge.

\section{The Gravlty Experiment Itself}

Launching and detecting such slow particles in an understandable way will be difficult. The pisneering experiment by Witteborn and Fairbank (20) with electrons has and will be a great help in investigating some of the possible systematic effects and errors. Table I lists some of the effects that must be considered. I shall discuss several of these effects. See Ret. (3) for inore detalls.

Table II. Sources of systematic errors.

1. End effects

2. The patch effect

3. Thompson emf

4. Electron sag

5. Lattice compression

6. Thermal fluctuations
7. Magnetic fleld unliformity

8. Alignment and tube uniformlty

9. Olf-axis orblts

10. Collisions with residual gas atorils

11. Neighbor Interactions

The patch effect occurs because the surface of even the best of conductors is 
not at a uniform potential because it consists of many crystal faces (patches) that can have differing work functions (21). The rms axial electric field produced by a random patch distribution on the surface of a typical corductor is estimated to be considerably larger than the gravitational equivalent (22). However, we expect to coat (23) the inner surface with an amorphous but still conducting material to reduce this field significantly. Furthermore, it has been discovered (22) that the patch field is strongly reduced at liquid-helium temperatures, although the reason for this suppression is not understood.

A temperature gradient along the dritt tube will cause a potential variation (Thompson emf) of a few $\mu \mathrm{V} / \mathrm{K}$. In our experiment we will need a temperature difference less than $10^{-2} \mathrm{~K}$. Immersing the entire tube in liquid helium cannot accomplish this, because the change in boiling point with pressure causes a temperature gradient of $0.3 \mathrm{~K} / \mathrm{m}$. However, it is possible (20) to reduce the gradient to $<10^{-5} \mathrm{~K} / \mathrm{m}$ by having the tube in contact with the helium bath at only one location (see Fig. 1 "Thermal Support Lirk").

The gravizational force on an antiproton at the earth's surface is equal to the electrostatic force between two antiprotons $12 \mathrm{~cm}$ apart. Thus the interaction of neighbor particles in the launch might seriously deplete the number of very low-energy particles. However, In a conducting tube the antiprotons are partially shielded from aach other. One finds that the effect is small compared to gravity if the antiprotons are separated by at leas: two to three times the tube's radius. The effect of such Coulomil forces on the velocity distribution of the launched particles is currently being studied by computer simulation. First results indicate that the number of particles per launch should be in the range of 10-100 to avoid a serious problem. This question will be studied experimentally in tests with $\mathrm{H}^{-}$lons.

\section{Present Status}

We have constructed at Los Alamos a test beam line to begin developing the apparatus for the antiproton gravity experiment. A $20 \mathrm{keV} \mathrm{H}$ beam, chopped to resemble an antlproton bunch is sent through a horizontal section consisting of valves, cold traps, four-way slits, vacuum pumps, magnetlc stererers, and electrostatic lenses. The beam is then turned into the vertical direction by a $90^{\circ}$ magnet mounted in a large vertical support stand. Above the $90^{\circ}$ magnet, the beam Is steered and focused into a Penning trap situated in the 6-T fleld of a superconducting solenold magnet.

Our ongoing tests with this apparatus will allow us to study vacuum isolation and bakeout procedures, ultimate vacuum capability with a room-temperature lon Irap, trap pulsing to capture protons or $\mathrm{H}^{-}$lons, the faatures needed in subsequent trap designs, and the type of $\mathrm{H}^{*}$ source to be taken to LEAR. To date, we have succeeded in passing a $10 \mu \mathrm{A}$ beam of $20 \mathrm{keV} \mathrm{H}$ ions through the trap's $3 \mathrm{~mm}$ diameter apertures in a 6.T magnetic field. We have also demonstrated simple trapping of NNN lons for TTT seconds by a fast raise of the voltages on the appropriate traps caps, followed by release and detection with an MCP. This is an Important step: capture of in-fllght lons has only recently been demonstrated (24).

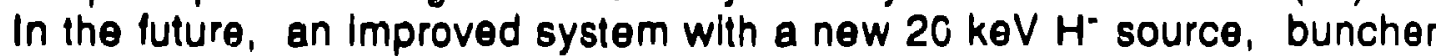
and RFQ decelerator will be constructed and installed at Los Alamos to receive a 2 $\mathrm{MeV} \mathrm{H} \mathrm{H}^{-}$beam trom the Los Alamos Vertical Van-de-Graaff. Research with this system will lead to a final cholce of traps and drift tube assembly, which In turn will be 
proof tested with $\mathrm{H}^{-}$ions before shipment to CERN for the antiproton experiment.

\section{Ackilowledgements}

Besides expressing appreciation to my colleagues (5) for discussions and help, I would like to thank D. C. Lizon, R. Martinez, R. R. Showalter, and C. B. Webb for their expert help in constructing and operating the present test system at the Los Alamos Ion Beam Facility.

This work was supported by the U.S. Department of Energy under Contract No. W7405 ENG-36. 


\section{Figure Captions.}

1. Schematic of an apparatus design for the time-of-flight antiproton gravity experiment. Ten $\theta \mathrm{V}$ antiprotons coming from below are trapped and cooled in the final Penning "launch" trap to a temperature of roughly $10 \mathrm{~K}$. The antiprotons would be extracted, a few at a time, to dritt up the shield tube; and, if not pulled back by gravity, accelerated to strike the detector. A rough scale is given by the $1-\mathrm{m}$ tall drift tube.

2. A possible schematic diagram for the Antiproton Gravity Experiment. The layout is a plan view except for the section after the electrostatic mirror which is a side view. The diagram is not to scale. The region inside the dotted lines represents a "thermal source" of low to very-low energy antiprntons that would be available for a variety of experiments.

3. Schematic cross section of a design for a first stage catching trap. The device is azimuthally symmetric about the horizontal axis. The entrance electrode is elongated to accomodate the beam burst length after some electrostatic deceleration. The Penning trap proper centers at the torus of circular cross section, and has a extended array of electrodes to provide a long trap that still has sufficient harmonicity for cooling. The entire trap length in this design is $50 \mathrm{~cm}$. 


\section{REFERENCES}

1. T. Goldman and M. M. Nieto, Phys. Lett. 112B, (1982) 437.

2. T. Goldman, R. J. Hughes, and M. M. Nieto, Phys. Lett. B171, (1986) 217; see also Ref. 10.

3. R.E. Brown, in $2^{\text {nd }}$ Conference on the Intersections between Particle and Nuclear Physics, Lake Louise, Canada, May, 1986.

4. R.J. Hughes, private commincation.

5. A recent list of collaboration members is given in ref. 3 .

6. N. Beverini, et al., CERN proposal P-94 (Los Alamos National Laboratory report LA-UR-86-260).

7. M. V. Hynes, in Physics with Antiprotons at LEAR in the ACOL Era, Proc. Third LEAP. Workshop, Tignes, Savoie, France, January, 1965, edited by U. Gastaldi, R. Klapisch, J. M. Richard, and J. Tran Thanh Van (éditions Frontières, Gif sur Yvette, 1985), p. 657.

8. R. E. Brown, in Workshop 017 the Design of a Low Energy Antimatter Facility in the USA, Madison, Wisconsin, Octcber, 1985 (American Institute of Physics).

9. M. H. Holzscheiter, in the Workshop of Ref. 8.

10. T. Goldman, in Antimaiter Physics at Low Energy, Fermilab Low Energy Antiproton Facility Workshop, April, 1986 (to be published by the Fermi National Accelerator Laboratory).

11. M. V. Hynes, in the Workshop of Rer. 6.

12. J. H. Billen, K. R. Crandall, T. P. Wangler, and M. Weiss, in Physics with Antiprotons at LEAR in the ACOL Era, Proc. Third LEAR Workshop, Tignes, Savoie, France, January, 1985, edited by $U$. Gastaldi, R. Klapisch, J. M. Richard, and J. Tran Thanh Van (éditions Frontières, Gif sur Yvette, 1985), p. 107.

13. F. lazzourene and K. Crandell, Privaie rommunication

14. J. Byrne and P. S. Farago, Proc. Phys. Soc. (London) 86, (1965) 801.

15. L.S. Brown and G. Sabrielse, Rev Mod. Phys. 58, (1986) 233.

16. R.A. Kenefick, Considerations for Electromagnetic Antiproton Traps, this conference.

17. D.A. Church, Highly-charged lons at Electron-Volt Energies and Below:

Production, Storage and Measurements, this conference.

18. L. Bracci, G. Florentini, and O. Pitzurra, Phys. Lett. 85B, (1979) 280. See also ref. 6.

19. W. Thompson, and S. Hanrahan, J. Vac. Sci. Technol. 14, (1977) 643.

20. F. C. Witteborn and W. M. Faimank, Phys. Rev. Lett. 19, (1967) 1049; Rev. Sci. Instium. 48, (1977) 1, this ref. discusses the design criteria and sources of error for the electron gravity experiment; F. C. Witteborn, Ph.D. thesis, Stanford University (1965).

21. C. Herring and M. H. Nichols, Rev. Med. Phys. 21, (1949) 185.

22. J. M. Lockhart, F. C. Witteborn, and W. M. Fairbank, Phys. Rev. Lett. 38 , (1977) 1220.

23. R. Mah, prlvate communication; S. Takayama, J. Mat. Scl. 11, (1976) 164.

24. H. Schnatz ot al., In-Flight Capture of lons into a Penning Trap, Submitted to Nucl. Instr. and Methods.; H.-J. Kluga, private communication. Also: G. Gabrielse and collaborators, Sclence, 233. 1383, (1986). 


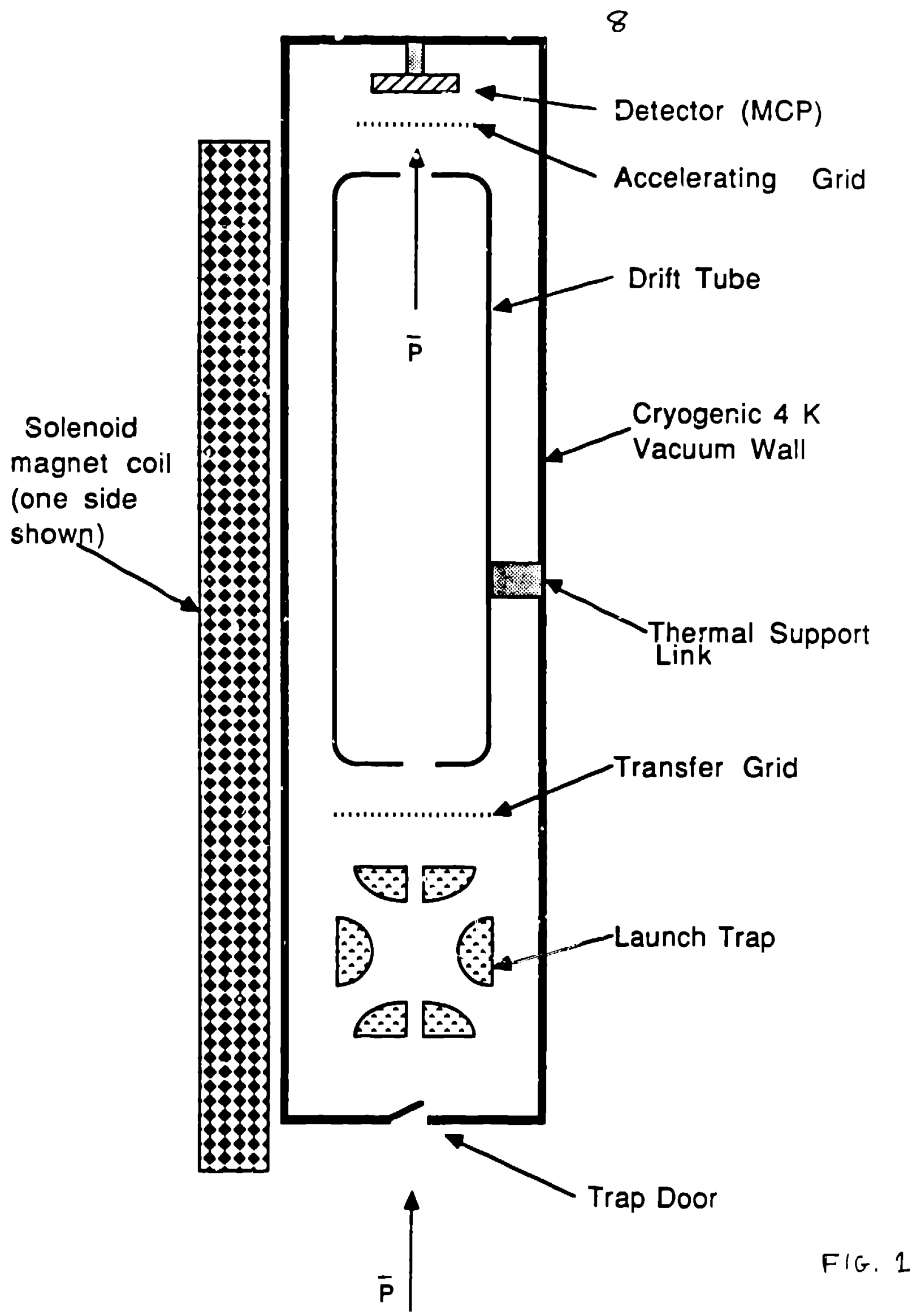

1. Schematic of en apparatus design for the time-of-flight antiproton gravity experiment. Ten $\theta \mathrm{V}$ antiprotons coming from below are trapped and cooled in the final Penning "launch" trap to a temperature of roughly $10 \mathrm{~K}$. The antiprotons vould bo extracted, a few at a time, to drift up the shield tube; and, if not pulled back by gravity, accelerated to strike the detector. A rough scale is given by the l-m tall dritt tube. 


\section{SCHEMATC LAYOUT ANTIPROTON GRAVITY EXPERIMENT}

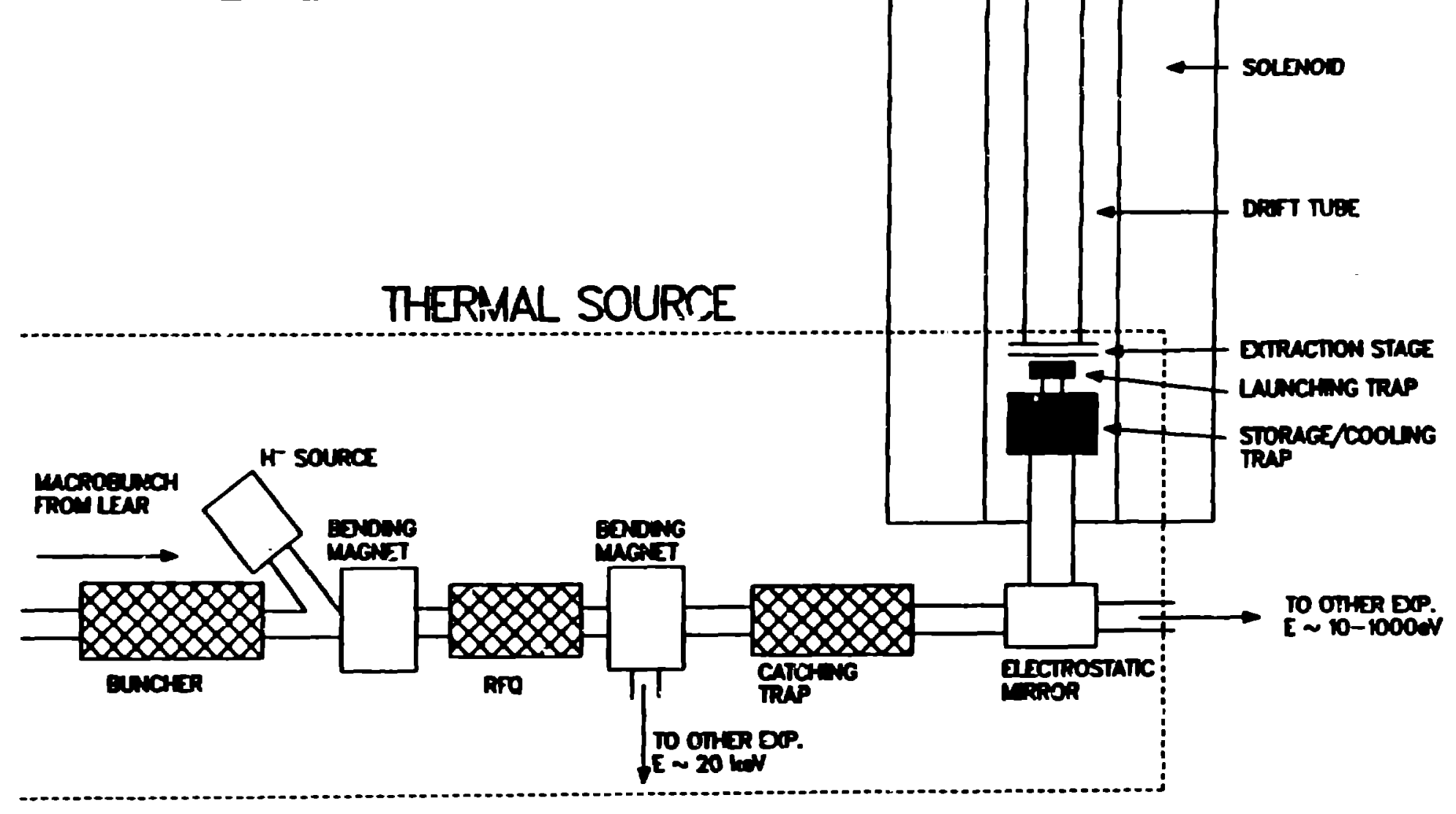

2. A possible schematic diagram for the Antiproton Gravity Experiment. The layout is a plan view except for the section after the electrostatic mirror which is a side view. The diagram is not to scale. The region inside the dotted lines represents a "thermal source" of low to very-low energy antiprotons that would be available for a variety of experiments. 


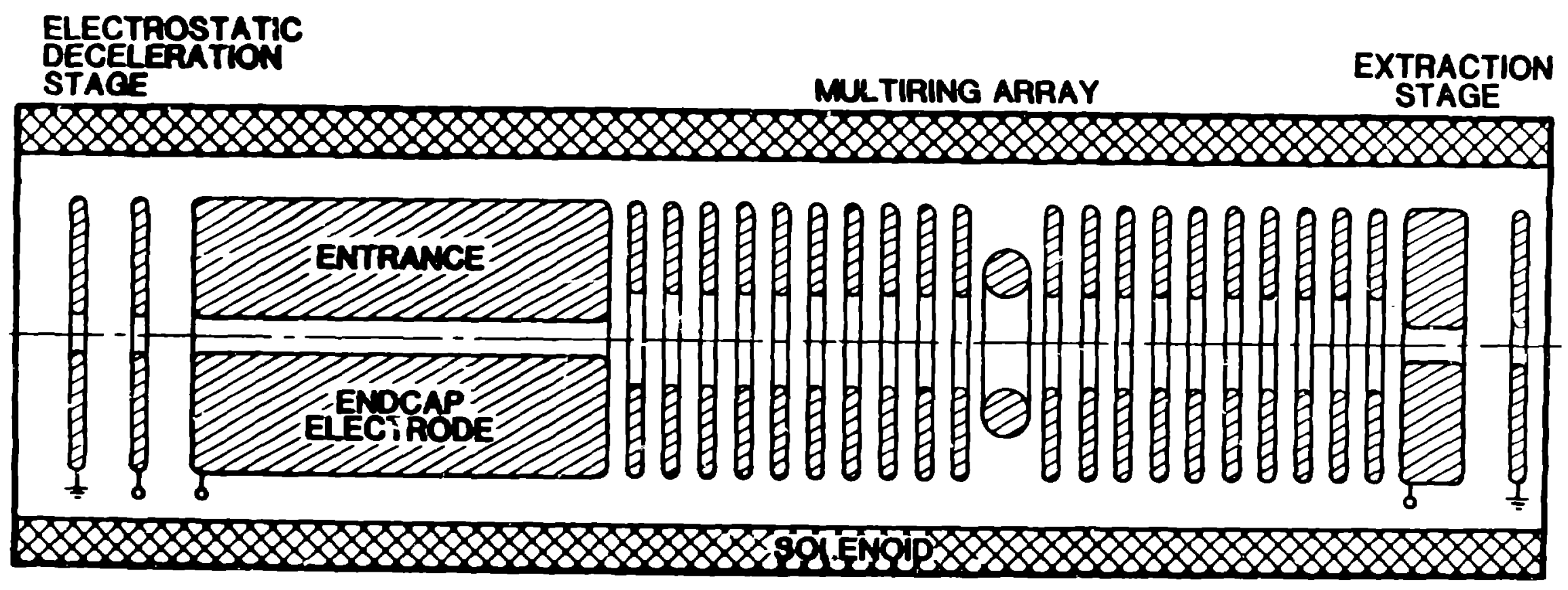

3. Schematic cross section of a design for a firs! stage catching trap. The device is azimuthally symmetric about the horizontal axis. The entrance electrode is elongated to accomodate the beam burst length after some electrostatic deceleration. The Penning trap proper centers at the torus of circular cross zection, and has a extended array of electrodes to provide a long trap that still has sufficient harmonicity for cooling. The entire trap length in this design is $50 \mathrm{~cm}$. 